\title{
SKALA KARAKTER WIRAUSAHA (SK-WIRA): KONSTRUKSI DAN VALIDASI AWAL
}

\author{
Aftina Nurul Husna, Aning Az Zahra, A. L. Amrul Haq \\ Fakultas Psikologi dan Humaniora, Universitas Muhammadiyah Magelang \\ Jl. Tidar No. 21 Magersari, Magelang Selatan, Kota Magelang, Indonesia 59214 \\ anhusna@ummgl.ac.id
}

\begin{abstract}
This article reports development of new scale to measure entrepreneurial characters. Entrepreneurial Characters Scale (SK-WIRA) measures personality traits indicating a person's capacity to engage in entrepreneurial activity and can be used to study tendency and suitability to work as entrepreneur. In preliminary study, entrepreneurial character is operationalized based on concepts found in literatures: achievement motivation, innovativeness, risk taking, and autonomy. Four SK-WIRA subscales were constructed according to those dimensions. In phase 1 item selection, exploratory factor analysis and reliability analysis were applied. Initial set of SK-WIRA constituted of 40-48 items per subscale was administered to university students $(\mathrm{N}=130)$. It is found that items were not clustered based on the theory, but item types (favorable-unfavorable). Therefore, it is predicted that entrepreneurial characters and non-entrepreneurial characters are probably two different constructs and need to be measured using different tools. Final compilation of SK-WIRA consists only 22 items (all is favorable items) with good internal consistency (Cronbach's $\alpha=.863$ ). Phase 2 construct validity test using confirmatory factor analysis (CFA) confirms that SK-WIRA consists of four correlated factors. The examination of scale internal structure shows good model fit $\left(\chi^{2} / d f=244.077 / 205 ; \mathrm{RMSEA}=.038 ; \mathrm{CFI}=.943 ; \mathrm{TLI}=.936 ; \mathrm{SRMR}=.069\right)$.
\end{abstract}

Keywords: entrepreneurial characters; scale development; psychology of entrepreneurship; Entrepreneurial Characters Scale/ SK-WIRA

\begin{abstract}
Abstrak
Artikel ini menyajikan upaya pengembangan skala psikologi baru untuk mengukur karakter wirausaha. Skala Karakter Wirausaha (SK-WIRA) mengukur sifat-sifat kepribadian yang menunjukkan kapasitas seseorang untuk berwirausaha dan dapat digunakan untuk menyelidiki kecenderungan dan kecocokan seseorang untuk menjadi pelaku usaha mandiri. Dalam studi pendahuluan, karakter wirausaha dioperasionalisasikan berdasarkan konsep yang ditemukan di literatur: motivasi berprestasi, keinovatifan, pengambilan risiko, dan otonomi. Empat subskala dari SK-WIRA dikembangkan berdasarkan empat dimensi tersebut. Pada tahap 1 seleksi item, dilakukan analisis faktor eksploratori (exploratory factor analysis/ EFA) dan analisis reliabilitas terhadap empat subskala SK-WIRA. Set awal SK-WIRA yang berisikan 40-48 item per subskala disebarkan kepada mahasiswa $(N=130)$. Ditemukan bahwa item-item tidak mengelompok berdasarkan dimensi teoretisnya, melainkan tipe favorabilitas-unfavorabilitas sehingga diperkirakan bahwa karakter wirausaha dan karakter bukan wirausaha adalah dua konstruk berbeda dan perlu diukur dengan alat ukur yang berbeda. Kompilasi final SK-WIRA hanya berisi 22 item (keseluruhannya adalah item-item favorabel) dan memiliki konsistensi internal yang baik (Alpha Cronbach $=0,863)$. Tahap 2 pemeriksaan validitas konstruk dengan confirmatory factor analysis (CFA) memastikan SK-WIRA terdiri atas empat dimensi yang berkorelasi. Pemeriksaan struktur internal skala dengan CFA menunjukkan model fit yang baik $\left(\chi^{2} / d f=244,077 / 205 ;\right.$ RMSEA $=0,038 ; \mathrm{CFI}=0,943 ; \mathrm{TLI}=0,936$; SRMR $=0,069$ ).
\end{abstract}

Kata kunci: karakter wirausaha; pengembangan skala; psikologi kewirausahaan; Skala Karakter Wirausaha (SK-WIRA)

\section{PENDAHULUAN}

Psikologi kewirausahaan adalah topik yang tengah naik daun (Frese \& Gielnik, 2014;
Hisrich, Langan-Fox, \& Grant, 2007; Shane \& Venkataraman, 2000) bersama dengan pesatnya pertumbuhan wirausaha global. Sebagaimana yang dilaporkan dalam Global 
Entrepreneurship Monitoring Report 2015 tentang kondisi kewirausahaan Indonesia, seiring dengan semakin positifnya pandangan terhadap wirausaha, berwirausaha semakin diminati sebagai pilihan karier yang menjanjikan kesuksesan, terutama oleh generasi muda, terlebih ketika unsur-unsur di masyarakat seperti pemerintah, institusi pendidikan, dan media pun mulai mendukung (Kelley, Singer, \& Herrington, 2015).

Aktivitas wirausaha terjadi ketika terdapat interaksi antara lingkungan yang memberikan kesempatan usaha dan pribadi individu yang mau berusaha (menangkap peluang, berinovasi menciptakan barang dan jasa, dan mengembangkan organisasi bisnis) (Shane \& Venkataraman, 2000). Meski demikian, fakta bahwa tidak semua orang mau dan mampu berkecimpung di bidang ini mengindikasikan adanya faktor-faktor yang mempengaruhi intensi berwirausaha, salah satunya adalah faktor individu. Riset-riset psikologi kewirausahaan terkini menemukan bahwa seorang wirausahawan memang memiliki karakter kepribadian yang khas (Frese \& Gielnik, 2014).

Pendekatan sifat merupakan yang pertama kali berkembang dalam khazanah psikologi kewirausahaan. Pendekatan ini bertujuan mengungkap profil wirausahawan dan mengidentifikasi karakter apa yang mendukung keberhasilan atau merugikan wirausaha. Pendekatan ini menyelidiki perbedaan antara usahawan-non usahawan atau usahawan sukses-gagal, serta mencari hubungan antara perbedaan karakter individual dan performa usahawan, kreasi, kebertahanan, dan kesuksesan bisnis (Rauch $\&$ Frese, 2000; 2007).

Shane dan Venkataraman (2000) merangkum bahwa terdapat berbagai faktor individual yang berpengaruh, sebagian di antaranya adalah karakter kepribadian. Karakter-karakter seperti kemampuan menahan risiko, optimisme, efikasi diri dan lokus kontrol internal, dan kemampuan menoleransi ketidakpastian sangat esensial terutama dalam kaitannya dengan kesediaan individu untuk memanfaatkan atau mengabaikan peluang. Temuan tersebut didukung oleh Frese dan Gielnik (2014) yang melakukan meta-analisis terhadap literatur-literatur psikologi kewirausahaan dan menyimpulkan bahwa wirausahawan cenderung lebih tinggi ketimbang manajer dalam efikasi diri, motivasi berprestasi, kecenderungan pada risiko, keinovatifan, toleransi stres, dan otonomi.

Brandstätter (2011) mengkaji lima studi meta-analisis tentang peran sejumlah karakter kepribadian pada wirausahawan dan manajer. Pertama, kecenderungan pada risiko (risk propensity), bahwa seorang wirausahawan lebih rentan menghadapi situasi berisiko, terutama yang berupa ketidakpastian. Situasi ini lantas menuntutnya untuk mampu mengatasi risiko, mampu membuat keputusan, dan tidak takut gagal. Kedua, motivasi berprestasi (achievement motivation) dan otonomi, bahwa orientasi pada tujuan dan pencapaian, hasrat untuk sukses, dan kebutuhan akan otonomi mencirikan wirausahawan terutama para pendiri usaha yang berorientasi pada kemajuan bisnis. Ketiga, dengan model kepribadian Big Five, seorang wirausahawan memiliki skor yang lebih tinggi ketimbang manajer dalam openness to experience (berkaitan dengan keinovatifan), conscientiousness (menjelaskan tingginya motivasi berprestasi), dan extraversion (berkaitan dengan kepribadian proaktif), sementara lebih rendah dalam agreeableness (berlawanan dengan kebutuhan otonomi dan independensi) dan neuroticism (berlawanan dengan efikasi diri, kemampuan menoleransi stres, dan lokus kontrol).

Temuan di atas tampak telah konklusif memastikan sifat kepribadian apa saja yang mencirikan seorang wirausahawan, tetapi terkesan pula kompleksitas karakter seorang wirausahawan. Upaya penyederhanaan konsep karakter wirausaha pun dilakukan dengan cara memeriksa sifat dan kekuatan 
sifat-sifat tersebut sebagai prediktor perilaku wirausaha. Rauch dan Frese (2007) mengklasifikasi karakter wirausaha menjadi dua jenis, yaitu sifat distal dan proksimal. Sifat distal merupakan sifat-sifat yang mengacu pada teori-teori kepribadian umum, seperti 16PF dan Model Big Five. Sifat-sifat distal merupakan prediktor kesuksesan wirausaha yang kuat, tetapi pengaruhnya dimediasi oleh sifat-sifat proksimal. Sifat proksimal adalah sifat-sifat khusus yang lebih dekat dalam menjelaskan perilaku wirausaha. Contoh sifat proksimal adalah motivasi berprestasi, pengambilan risiko, keinovatifan, lokus kontrol, dan efikasi diri wirausaha. Menurut Rauch dan Frese (2007) kedua jenis sifat tersebut bekerja dengan cara yang berbeda. Sifat kepribadian umum lebih berperan dalam hal penentuan tujuan dan pembangunan strategi yang selanjutnya mempengaruhi kreasi bisnis dan kesuksesan. Peran sifat kepribadian umum dimediasi oleh sifat-sifat khusus yang mempengaruhi pemilihan strategi tindakan.

Berdasarkan hal tersebut, maka karakter wirausahawan yang sesungguhnya dapat difokuskan pada sifat-sifat proksimal yang memiliki kaitan langsung dengan perilaku usaha yang nyata di lapangan. Para ahli berbeda pendapat mengenai karakter apa saja yang termasuk dalam sifat proksimal (Brandstätter, 2011; Frese, 2009; Frese \& Gielnik, 2014), tetapi secara garis besar dapat disimpulkan ada empat karakter utama, yaitu: motivasi berprestasi, keinovatifan, pengambilan risiko, dan otonomi (Walter \& Heinrich, 2013).

Motivasi berprestasi erat kaitannya dengan kebutuhan akan prestasi yang merupakan motif paling prinsipil dalam aktivitas wirausaha (Chen, Su, \& Wu, 2012; Wu, Matthews, \& Dagher, 2007). McClelland (dalam Stewart \& Roth, 2001) menjelaskan motivasi ini berkenaan dengan hasrat untuk melakukan yang terbaik, mencapai kepuasan, dan rasa berhasil dari suatu pencapaian. Dalam konteks kewirausahaan, motivasi berprestasi menjelaskan komitmen dan kegigihan kerja seorang usahawan. Orang yang bermotivasi berprestasi tinggi cenderung senang pada tugas-tugas yang menuntut tanggung jawab pribadi, keahlian, dan kerja keras (Stewart \& Roth, 2001; Utsch \& Rauch, 2000). Sejauh ini motivasi berprestasi berusaha diukur dengan Achievement Motive Questionnairel AMQ yang dikembangkan oleh Sagie dan Elizur (1999). Motivasi berprestasi adalah konstruk multidimensional dengan tiga aspek: instrumental (kebiasan melakukan), afektif (rasa puas), dan kogntif (sikap dan preferensi) pada tugas-tugas yang menantang (melibatkan hasil yang tak pasti, sulit, meminta tanggung jawab personal, melibatkan risiko, dan menuntut pemecahan masalah) (Sagie \& Elizur, 1999).

Keinovatifan merupakan ciri utama kewirausahaan. Potensi berwirausaha seseorang biasanya dapat diketahui dari seberapa inovatif seseorang (Mueller \& Thomas, 2000). Keinovatifan merupakan perilaku inovatif aktual yang berorientasi pada peningkatan produk melalui pelahiran gagasan, proses, dan prosedur baru. Keinovatifan seseorang tampak dari kesenangannya mencoba hal-hal baru sehingga tugas diselesaikan secara lebih efektif dan efisien. (Utsch \& Rauch, 2000). Selain itu, keinovatifan dapat pula dipahami sebagai sikap terhadap inovasi, berupa keterbukaan seseorang pada inovasi, kesediaan beradaptasi dengan kebaruan, dan kecenderungan mengadopsi inovasi lebih dulu daripada orang lain (Goldsmith \& Foxall, 2003; Marcati, Guido, \& Peluso, 2008). Sejauh yang penulis temukan, belum ada alat ukur keinovatifan wirausahawan. Adapun yang telah dikembangkan adalah pengukuran keinovatifan konsumen (Goldsmith \& Foxall, 2003).

Pengambilan risiko berkenaan dengan orientasi mengambil peluang dan melibatkan ketidakpastian hasil (Chen, Su, \& Wu, 2012). Aktivitas wirausaha melibatkan lebih banyak risiko lantaran jenis pekerjaannya yang minim struktur, melibatkan banyak 
kemungkinan dan ketidakpastian. Wirausahawan pun dikenal memiliki kecenderungan dan toleransi terhadap risiko yang lebih baik (Antonites \& Wordsworth, 2009). Wirausahawan membangun adaptasi terhadap risiko dengan cara memiliki persepsi positif (optimistik) tentang risiko. Risiko tidak dipahami dalam kaitannya dengan kegagalan dan sebagai ancaman, melainkan pilihan yang diambil demi kemungkinan mendapatkan keuntungan lebih (Palich \& Bagby, 1995). Pengambilan risiko dapat diukur dengan Choice Dilemmas Questionnairel CDQ (Wallach \& Kogan dalam Brockhaus, 1980).

Terakhir, otonomi atau kemandirian adalah semangat independen dan kebebasan melakukan tindakan yang dibutuhkan untuk memajukan usaha dan melaksanakan inisiatif-inisiatif bisnis. Otonomi dicirikan oleh independensi dalam bertindak. Otonomi yang tinggi memungkinkan seseorang bekerja di luar tradisi, rutinitas, dan kebiasaan, serta meski tanpa ada perintah sehingga otonomi menjadi kualitan yang menentukan kemajuan inovasi, kompetisi, dan efektivitas kerja (Lumpkin, Cogliser, \& Schneider, 2009). Otonomi adalah kebutuhan dalam diri untuk berkehendak, bertanggung jawab atas diri sendiri, membuat pilihan, dan beraktivitas secara bebas tanpa kekangan psikologis (Broeck, Vansteenkiste, Witte, Soenens, \& Lens, 2010). Dalam kewirausahaan, kualitas ini penting karena banyak orang berwirausaha karena ingin menjadi diri sendiri atau menjadi tuan dalam hidup sendiri. Otonomi yang tinggi menandakan lokus kontrol internal yang tinggi, dan selanjutnya berkontribusi dalam meningkatkan motivasi berprestasi dan membangun keahlian untuk mencapai kesuksesan (Rauch \& Frese, 2007; Ryan \& Deci, 2000). Konsep otonomi diambil dari Teori Determinasi Diri yang merumuskan adanya kebutuhan psikologi dasar, kompetensi, keterhubungan, dan otonomi (Ryan \& Deci, 2000).
Karakter wirausaha dapat dikonseptualisasikan sebagai derajat sejauh mana seseorang memiliki empat kualitas utama tersebut, yaitu: motivasi berprestasi yang tinggi, inovatif, sedia mengambil risiko, dan memiliki otonomi yang tinggi. Empat kualitas ini diperkirakan dapat menjadi acuan untuk mengungkap kapasitas seseorang dalam berwirausaha atau mengidentifikasi kecenderungan dan kecocokan seseorang untuk berkarir sebagai wirausahawan.

Dalam literatur psikologi kewirausahaan saat ini, penulis belum menemukan adanya instrumen yang mengukur motivasi berprestasi, keinovatifan, pengambilan risiko, dan otonomi dalam konteks kewirausahaan. Seluruh instrumen kewirausahaan yang sudah ada dikembangkan dalam bahasa Inggris sehingga perlu adaptasi untuk digunakan di Indonesia. Sebagian dikembangkan sebagai konstruk psikologis umum pada konteks non-kewirausahaan, seperti kepegawaian di tempat kerja (misal Broeck dkk, 2010), perilaku konsumen (Goldsmith \& Foxall, 2003), dan olahraga (Vlachopoulos \& Michailidou, 2006). Selain itu, instrumeninstrumen tersebut pun menjadikan individu dewasa yang sudah bekerja sebagai sasaran (Lumpkin dkk, 2009)

Lantaran hal tersebut, patut menjadi perhatian bahwa kebutuhan yang perlu dipenuhi saat ini adalah alat ukur yang dapat dimanfaatkan untuk riset kewirausahaan di Indonesia dan dapat digunakan untuk mendukung kepentingan peningkatan angka wirausahawan baru terutama dari kalangan anak muda yang sering disebut-sebut sebagai generasi milenial. Anak muda yang kini berjumlah lebih dari 60 juta jiwa lebih atau sekitar $40 \%$ dari total angkatan kerja Indonesia sangat disarankan untuk berwirausaha berdasarkan analisis Badan Perencanaan dan Pembangunan Nasional (Bappenas) (Suryanto, 2017). Keberhasilan generasi muda untuk menjadi pengusaha dinilai lebih baik ketimbang kelompok umur 
lainnya karena selain dibekali kepercayaan diri dan kreativitas lebih, mereka juga memiliki jaringan pergaulan yang luas dan kemampuan memanfaatkan teknologi digital (Maulana, 2018).

Berdasarkan latar belakang kebutuhan tersebut, penelitian ini pun bertujuan untuk mengembangkan Skala Karakter Wirausaha/ SK-WIRA. Adapun pertanyaan yang berusaha dijawab adalah: 1) Bagaimana konstruksi karakter wirausaha dalam SKWIRA? 2) Bagaimana properti psikometrik (dimensionalitas, reliabilitas, dan validitas) SK-WIRA?

\section{METODE}

\section{Operasionalisasi Variabel dan Konstruksi Skala}

Konsep karakter wirausaha dikembangkan berdasar hasil studi terhadap artikel-artikel penelitian dan teoretis yang membahas sifatsifat wirausahawan. Sebanyak 48 artikel ditemukan lewat mesin pencari Google Scholar dalam rentang waktu tahun 19612015 secara umum dengan kata kunci entrepreneurial traits dan entrepreneur characters, serta lebih detail lagi dengan kata kunci achievement motivation, innovativeness, risk taking, dan autonomy dalam konteks kewirausahaan. Hasil akhir dari studi literatur tersebut adalah operasionalisasi konsep karakter wirausaha sebagai konsep yang terdiri atas empat komponen, yakni motivasi berprestasi, keinovatifan, pengambilan risiko, dan otonomi. Hal tersebut dapat dilihat pada Tabel 1.

SK-WIRA dirancang sebagai skala multidimensional dan terdiri atas empat subskala. Subskala 1 Motivasi Berprestasi terdiri atas 48 item, Subskala 2 Keinovatifan 48 item, Subskala 3 Pengambilan risiko 40 item, dan Subskala 4 Otonomi 40 item sehingga total 176 item. SK-WIRA menggunakan format respon skala Likert dengan rentang nilai 1-5 yang berarti sangat tidak sesuai, tidak sesuai, agak sesuai, sesuai, dan sangat sesuai. Skala ini mengandung item favorable dan unfavorable dengan proporsi yang seimbang.

Tabel 1.

Operasionalisasi Konsep Karakter Wirausaha

\begin{tabular}{|c|c|}
\hline \multirow{2}{*}{$\begin{array}{l}\text { Komponen } \\
\text { Motivasi Berprestasi }\end{array}$} & Aspek dan Indikator Perilaku \\
\hline & $\begin{array}{l}\text { Sebagai dorongan berperilaku yang bersumber dari adanya kebutuhan akan } \\
\text { prestasi, motivasi berprestasi terdiri atas tiga aspek, yaitu: instrumental, } \\
\text { afektif, dan kognitif. } \\
\text { 1. Instrumental adalah perilaku menjalankan atas inisiatif sendiri tugas- } \\
\text { tugas menantang. Indikator: Bersedia melaksanakan tugas-tugas yang } \\
\text { menantang, dan biasa melakukan tugas-tugas yang menantang. } \\
\text { 2. Afektif adalah rasa puas dan senang dari melakukan tugas-tugas yang } \\
\text { menantang. Indikator: Mendapatkan rasa puas dari melaksanakan tugas- } \\
\text { tugas yang menantang, dan merasakan kesenangan dalam mengerjakan } \\
\text { tugas-tugas yang menantang. } \\
\text { 3. Kognitif adalah keyakinan yang menunjukkan level preferensi } \\
\text { seseorang untuk mengerjakan tugas-tugas yang menantang. Indikator: } \\
\text { Memilih mengerjakan tugas-tugas yang menantang ketimbang yang } \\
\text { kurang menantang, dan meningkatkan target ketika mendapati tugas } \\
\text { kurang menantang. }\end{array}$ \\
\hline
\end{tabular}


Lanjutan Tabel 1. Operasionalisasi Konsep Karakter Wirausaha

Keinovatifan Sebagai kecenderungan seseorang mengembangkan dan menerapkan gagasan, proses, atau prosedur baru, keinovatifan terdiri atas tiga aspek, yaitu: sikap, responsivitas, dan implementasi.

1. Sikap adalah pendapat berdasarkan penilaian positif atau negatif terhadap keinovatifan. Indikator: Membuka diri terhadap kebaruan, dan bersedia beradaptasi dengan hal-hal baru.

2. Responsivitas adalah seberapa tanggap seseorang terhadap kebaruan, menunjukkan kesiapannya untuk secara aktual segera mengikuti perubahan dan mengadopsinya lebih dulu ketimbang orang lain. Indikator: Lebih peka terhadap informasi tentang inovasi ketimbang orang lain, dan bersegera mengadopsi inovasi sebelum orang lain melakukan hal yang sama.

3. Implementasi adalah seberapa sering seseorang mencoba menggunakan cara-cara baru dalam mengerjakan tugasnya. Indikator: Mencari informasi tentang metode/ teknik penggunaan prosedur yang baru, dan merencanakan penggunaan prosedur baru

Pengambilan Risiko Sebagai kecenderungan seseorang mengambil peluang dalam konteks pengambilan keputusan yang hasilnya tak pasti, pengambilan risiko terdiri atas dua aspek, yaitu: persepsi optimistik dan toleransi risiko.

1. Persepsi optimistik adalah kecenderungan menginterpretasi situasi yang mengancam sebagai mengandung peluang untuk sukses ketimbang kemungkinan untuk gagal. Indikator: Berkeyakinan positif bahwa situasi yang mengancam mengandung peluang untuk sukses, dan mendeteksi adanya kekuatan dan kesempatan dari situasi yang mengandung kelemahan dan ancaman.

2. Tolerasi risiko adalah kesediaan menerima risiko ketimbang menolak dan menghindarinya. Indikator: Membuat perhitungan objektif (tidak emosional) tentang kekuatan dan kelemahan sebelum mengambil keputusan berisiko, menerima ada kemungkinan gagal dalam setiap pengambilan keputusan, dan mengambil risiko sebagai bagian dari proses mencapai hasil yang diinginkan.

Otonomi Sebagai kecenderungan untuk bertindak berdasarkan inisiatif sendiri, tanpa tergantung dari pengaruh, tekanan atau perintah orang lain, otonomi terdiri atas dua aspek: determinasi diri dan tindakan mandiri.

1. Determinasi diri adalah kehendak untuk menentukan jalan hidup sendiri atas dasar kehendak dan pilihan-pilihan pribadi, bukan pengaruh orang lain. Indikator: Ingin mengembangkan pilihan, minat, dan citacita pribadi ketimbang meniru mayoritas orang, dan ingin mewujudkan bakat dan kemampuan yang dimiliki diri tanpa dipaksa orang lain.

2. Tindakan mandiri adalah kemampuan melakukan tugas-tugas yang memberikan kebebasan untuk mengambil tindakan yang diperlukan berdasar inisiatif sendiri, bukan perintah atau kebiasaan. Indikator: Mampu bekerja tanpa perlu diperintah oleh otoritas atau diatur oleh norma dan kebiasaan, mampu memutuskan tujuan dan rencana tindakan terkait pengerjaan suatu tugas tanpa dipengaruhi orang lain, dan mampu mengontrol usaha-usaha pencapaian tujuan tanpa perlu diawasi oleh orang lain.

Setelah seluruh skala tersusun, SK-WIRA melewati pemeriksaan validitas isi dengan evaluasi yang melibatkan dua orang pakar psikologi dalam tim riset ini. Validitas isi diperiksa dengan metode Aiken's V dengan hasil beberapa item dengan skor kurang dari 0,5 perlu direvisi agar sesuai dengan aspeknya. Sebelum skala diujicobakan, validitas tampang diperiksa dengan bantuan 
dua orang mahasiswa untuk mengetahui keterbacaan skala.

\section{Partisipan dan Prosedur Pengambilan Data}

Data dikumpulkan selama Februari-Maret 2018 dengan bantuan enam orang mahasiswa asisten penelitian. Partisipan penelitian ini adalah mahasiswa di Magelang dengan teknik convenient sampling $(\mathrm{N}=$ 130). Dari target 200 kuesioner, kembali 177 kuesioner yang terisi. Di antara kuesioner tersebut, sebanyak 47 kuesioner diisi oleh responden yang masih pelajar dan yang sudah bekerja sehingga tidak sesuai dengan tujuan penelitian. Pada akhirnya, hanya 130 kuesioner yang dianalisis lebih lanjut. Adapun karakteristik partisipan terlihat pada Tabel 2.

\section{Analisis Data}

Diterapkan tiga teknik statistik untuk menganalisis data dalam tiga tahap. Pada tahap pertama, eksplorasi dan seleksi item, peneliti menggunakan Exploratory Factor Analysis (EFA) untuk memeriksa dimensi skala dan menghitung koefisien alpha Cronbach untuk memeriksa konsistensi internal skala. Pada tahap kedua, pemeriksanaan validitas konstruk, peneliti menggunakan Confirmatory Factor Analysis (CFA). Untuk menjalankan prosedur statistik EFA dan uji reliabilitas, peneliti menggunakan program IBM SPSS Statistics
20, sementara untuk CFA, peneliti menggunakan program MPlus.

Tabel 2.

Karakteristik Partisipan

\begin{tabular}{lc}
\hline Keterangan & Jumlah \\
\hline Jenis Kelamin & \\
Pria & $60(46,2 \%)$ \\
Wanita & $70(53,8 \%)$ \\
\hline Usia (tahun) & \\
Range & $17-26$ \\
Mean & 20,03 \\
SD & 1,54 \\
\hline Pengalaman Berwirausaha & \\
Pernah & $71(54,6 \%)$ \\
Belum pernah & $59(45,4 \%)$ \\
\hline
\end{tabular}

\section{HASIL DAN PEMBAHASAN}

Sebelum dilakukan analisis atas data, peneliti terlebih dahulu memeriksa hal-hal yang mungkin mengancam kualitas psikometrik skala. Berdasarkan laporan tim pengumpul data di lapangan, ada kecenderungan para responden bosan dengan skala yang panjang. Peneliti mengantisipasi kemungkinan terjadinya bias respon acquiescence atau "yea-saying" dengan mencari apakah ada item dengan frekuensi jawaban terhadap salah satu opsi lebih dari 75\%. Hasilnya, peneliti tidak menemukan adanya persoalan acquiescence. Karakter distribusi data terlihat pada Tabel 3.

Tabel 3.

Karakter Distribusi Data

\begin{tabular}{llll}
\hline Subskala & Tes Shapiro-Wilk & Skewness & Kurtosis \\
\hline Motivasi Berprestasi & $0,967(\mathrm{p}<0,05)$ & $0,563(\mathrm{SE}=0,212)$ & $-0,137(\mathrm{SE}=0,422)$ \\
\hline Keinovatifan & $0,965(\mathrm{p}<0,05)$ & $0,602(\mathrm{SE}=0,212)$ & $0,187(\mathrm{SE}=0,422)$ \\
\hline Pengambilan Risiko & $0,967(\mathrm{p}<0,05)$ & $0,492(\mathrm{SE}=0,212)$ & $0,093(\mathrm{SE}=0,422)$ \\
\hline Kemandirian & $0,942(\mathrm{p}<0,01)$ & $0,948(\mathrm{SE}=0,212)$ & $1,328(\mathrm{SE}=0,422)$ \\
\hline
\end{tabular}

Distribusi data tampak cenderung condong kanan (positively skewed). Hasil pemeriksaan normalitas data dengan tes Shapiro-Wilk dan pemeriksaan visual terhadap histogram dan normal QQ-plots menunjukkan distribusi skor keempat subskala cenderung tidak normal.
Ketidaknormalan distribusi data wajar terjadi, tetapi berdampak pada pemilihan metode rotasi ketika dilakukan EFA. Untuk distribusi data yang tidak normal, disarankan untuk menggunakan Principal Axis Factoring (Costello \& Osborne, 2005). 
Tahap 1 Eksplorasi dan Seleksi Item

Dalam EFA, digunakan metode ekstraksi Principal Axis Analysis/ PAF, metode rotasi oblique (Promax), dan menetapkan eigenvalue $>1$. Jumlah dimensi atau faktor dilihat dari grafik scree plot di mana jumlah dimensi dapat diketahui dari jumlah titik yang ada sebelum grafik melandai di "siku". Sementara itu, reliabilitas skala diketahui lewat pemeriksaan konsistensi internal
Alpha Cronbach. Kriteria yang digunakan untuk seleksi item adalah memiliki factors loading $>0,30$. bukan item cross-loading, dan memiliki koefisian korelasi item-total ( $\mathrm{r}_{\mathrm{i}-}$ x) >0,30. Hasil EFA keempat subskala disajikan di Tabel 4-7. Demi tujuan efisiensi, tabel disederhanakan dengan hanya memuat faktor yang berisi $>5$ item dan hanya menampilkan 10 item dengan factor loading terbaik di setiap faktor.

Tabel 4.

Factors Loading Item-item dalam Subskala Motivasi Berprestasi

\begin{tabular}{clrr}
\hline \multirow{2}{*}{$\begin{array}{c}\text { Nomor } \\
\text { Item }\end{array}$} & \multicolumn{1}{c}{ Inti Pernyataan } & \multicolumn{2}{c}{ Faktor } \\
\cline { 3 - 4 } & & 1 & \multicolumn{1}{c}{2} \\
\hline mb35 & Lebih suka tugas-tugas yang tidak merepotkan* & $\mathbf{0 , 6 5 1}$ & $-0,303$ \\
\hline mb43 & Lebih nyaman dengan tugas-tugas yang minim risiko* & $\mathbf{0 , 6 4 0}$ & $-0,236$ \\
\hline mb28 & Takut menghadapi tugas di luar kemampuan* & $\mathbf{0 , 6 2 7}$ & $-0,284$ \\
\hline mb31 & Enggan bekerja sendirian, takut hasil tak memuaskan* & $\mathbf{0 , 6 2 4}$ & $-0,230$ \\
\hline mb15 & Meminta pekerjaan sulit diberikan kepada orang lain* & $\mathbf{0 , 6 2 3}$ \\
\hline mb44 & Yang penting tugas selesai, bukan kualitas hasil* & $\mathbf{0 , 6 1 1}$ & \\
\hline mb48 & Mencukupkan diri pada standar minimal* & $\mathbf{0 , 5 8 7}$ & $-0,321$ \\
\hline mb47 & Mengambil tugas yang mudah ketimbang yang susah* & $\mathbf{0 , 5 6 8}$ & $-0,243$ \\
\hline mb20 & Malas menghadapi persoalan-persoalan baru* & $\mathbf{0 , 5 6 2}$ & \\
\hline mb36 & Memilih metode pengerjaan tugas yang umum* & $\mathbf{0 , 5 4 6}$ & $-0,246$ \\
\hline mb30 & Mencari tantangan baru setelah selesai satu tugas & 0,413 & $\mathbf{0 , 5 5 4}$ \\
\hline mb37 & Yakin potensi diri ketika diberi tugas di luar bidang & & $\mathbf{0 , 5 5 1}$ \\
\hline mb26 & Terus belajar mengantisipasi persoalan baru & 0,312 & $\mathbf{0 , 4 9 0}$ \\
\hline mb03 & Bisa mengerjakan tugas sulit tidak mengagumkan* & & $\mathbf{- 0 , 4 8 5}$ \\
\hline mb32 & Antusias jika bisa berkontribusi dalam tugas kelompok & 0,311 & $\mathbf{0 , 4 4 1}$ \\
\hline mb01 & Suka tugas yang menantang kemampuan & 0,378 & $\mathbf{0 , 4 4 0}$ \\
\hline mb06 & Mencari cara agar hasil sempurna & 0,375 & $\mathbf{0 , 4 3 6}$ \\
\hline mb10 & Terbiasa dengan tugas yang sulit & 0,240 & $\mathbf{0 , 4 2 7}$ \\
\hline mb29 & Memilih tugas yang menuntut kemampuan sendiri & $\mathbf{0 , 4 2 4}$ \\
\hline mb05 & Suka tugas yang memberikan pengalaman baru & 0,390 & $\mathbf{0 , 4 1 8}$ \\
\hline Ket: * item unfavorable & & &
\end{tabular}

Tabel 5.

Factors Loading Item-item dalam Subskala Keinovatifan

\begin{tabular}{clll}
\hline \multirow{2}{*}{$\begin{array}{c}\text { Nomor } \\
\text { Item }\end{array}$} & \multicolumn{1}{c}{ Inti Pernyataan } & \multicolumn{2}{c}{ Faktor } \\
\cline { 3 - 3 } & & $\mathbf{0 , 7 5 3}$ \\
\hline inv27 & Menolak cara baru karena nyaman dengan yang lama* & $\mathbf{0 , 7 5 1}$ \\
\hline inv35 & Bertahan dengan cara lama karena hal baru merepotkan* & $\mathbf{0 , 7 4 3}$ \\
\hline inv44 & Tetap pada tradisi sampai dipaksa berubah* & $\mathbf{0 , 7 2 4}$ \\
\hline inv29 & Menyesal mencoba cara baru yang gagal* & \\
\hline
\end{tabular}




\begin{tabular}{clrl}
\hline \multicolumn{2}{l}{ Lanjutan Tabel 5. Factors Loading Item-item dalam Subskala Keinovatifan } \\
\hline inv38 & Tidak punya waktu belajar gagasan baru* & $\mathbf{0 , 7 2 4}$ & \\
\hline inv48 & Berpikir inovasi adalah tipuan* & $\mathbf{0 , 7 1 9}$ & \\
\hline inv46 & Mempertahankan tradisi karena hal baru tidak pasti* & $\mathbf{0 , 6 8 9}$ & \\
\hline inv19 & Nyaman dengan teknik kerja yang lama* & $\mathbf{0 , 6 7 6}$ & \\
\hline inv31 & Memperbarui teknik setelah dipaksa keadaan* & $\mathbf{0 , 6 6 7}$ & \\
\hline \multirow{2}{*}{ inv40 } & Kembali pada cara lama karena tidak biasa dengan hal & $\mathbf{0 , 5 7 8}$ & \\
& baru* & & $\mathbf{0 , 7 0 0}$ \\
\hline inv14 & Senang mengikuti berita inovasi & 0,281 & $\mathbf{0 , 7 0 0}$ \\
\hline inv43 & Senang masyarakat berinovasi & $\mathbf{0 , 6 6 4}$ \\
\hline inv24 & Ingin memperbarui teknik dengan yang lebih efektif & $\mathbf{0 , 6 4 1}$ \\
\hline inv26 & Mengumpulkan modal untuk memperbarui teknologi & 0,247 & $\mathbf{0 , 6 2 5}$ \\
\hline inv21 & Belajar agar dapat menyesuaikan diri dengan kemajuan & $\mathbf{0 , 6 1 0}$ \\
\hline inv45 & Mencari tahu kekurangan dari prosedur baru yang gagal & & $\mathbf{0 , 6 0 7}$ \\
\hline inv37 & Berusaha agar dapat memanfaatkan teknik baru & 0,224 & $\mathbf{0 , 5 7 2}$ \\
\hline inv04 & Lebih giat berlatih menggunakan cara baru & $\mathbf{0 , 5 6 4}$ \\
\hline inv06 & Bersyukur era modern penuh inovasi & $\mathbf{0 , 5 6 4}$ \\
\hline inv41 & Bertanya lebih jauh tentang ide baru &
\end{tabular}

Ket: * item unfavorable

Tabel 6.

Factors Loading Item-item dalam Subskala Pengambilan Risiko

\begin{tabular}{|c|c|c|c|}
\hline \multirow{2}{*}{$\begin{array}{l}\text { Nomor } \\
\text { Item }\end{array}$} & \multirow[t]{2}{*}{ Inti Pernyataan } & \multicolumn{2}{|c|}{ Faktor } \\
\hline & & 1 & 2 \\
\hline pr35 & $\begin{array}{l}\text { Merasa kehilangan kesempatan berkembang karena } \\
\text { tidak ada dukungan* }\end{array}$ & 0,692 & \\
\hline pr39 & Merasa ditakdirkan gagal karena kesulitan-kesulitan* & 0,652 & 0,430 \\
\hline pr36 & Menjauhkan diri dari situasi yang penuh masalah* & 0,624 & \\
\hline pr19 & Merasa ada terlalu banyak masalah yang rumit* & 0,614 & 0,432 \\
\hline pr31 & Mementingkan keuntungan, mengabaikan risiko* & 0,613 & 0,380 \\
\hline pr07 & Benci jika gagal* & 0,612 & \\
\hline $\mathrm{pr} 40$ & Kekurangan membuat diri merasa lebih buruk* & 0,604 & 0,203 \\
\hline pr20 & Merasa tidak berbakat karena gagal* & $\mathbf{0 , 5 8 3}$ & 0,426 \\
\hline pr23 & $\begin{array}{l}\text { Memilih prosedur yang umum ketimbang yang lebih } \\
\text { efektif tapi tak populer* }\end{array}$ & $\mathbf{0 , 5 3 1}$ & \\
\hline $\operatorname{pr} 15$ & Merasa prestasi terbaik sudah berlalu* & $\mathbf{0 , 5 2 9}$ & 0,270 \\
\hline pr02 & Yakin kegagalan sumber pelajaran & & $\mathbf{0 , 5 8 7}$ \\
\hline pr26 & Menjajaki jalan lain ketika gagal & $-0,298$ & $\mathbf{0 , 5 6 4}$ \\
\hline pr13 & Mengantisipasi kegagalan dengan strategi alternatif & $-0,282$ & $\mathbf{0 , 5 5 7}$ \\
\hline pr01 & Percaya setiap masalah punya solusi & & $\mathbf{0 , 5 3 4}$ \\
\hline pr06 & Yakin kesulitan membuat diri lebih tangguh & & $\mathbf{0 , 5 0 4}$ \\
\hline pr22 & Kondisi tak ideal adalah sumber pelajaran & $-0,241$ & $\mathbf{0 , 5 0 1}$ \\
\hline pr18 & Memilih jalan yang sulit tapi lebih memuaskan & $-0,225$ & $\mathbf{0 , 4 3 3}$ \\
\hline
\end{tabular}




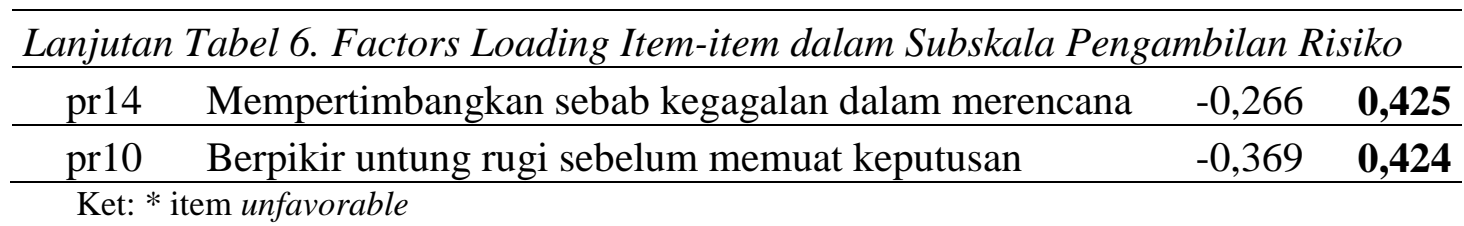

Tabel 7.

Factors Loading Item-item dalam Subskala Kemandirian

\begin{tabular}{rlrc}
\hline \multirow{2}{*}{$\begin{array}{c}\text { Nomor } \\
\text { Item }\end{array}$} & \multicolumn{1}{c}{ Inti Pernyataan } & \multicolumn{2}{c}{ Faktor } \\
\cline { 3 - 4 } oto35 & Menjadi ragu jika keputusan ditolak* & $\mathbf{0 , 5 6 1}$ & 0,437 \\
\hline oto22 & Rencana yang dibuat mencerminkan target & $\mathbf{- 0 , 5 4 2}$ & 0,457 \\
\hline oto06 & Tahu apa yang diinginkan & $\mathbf{- 0 , 5 2 9}$ & 0,354 \\
\hline oto15 & Sulit berkerja jika tidak diberi batas waktu* & $\mathbf{0 , 5 2 8}$ \\
\hline oto20 & Enggan berkerja jika tidak diperintah* & $\mathbf{0 , 5 2 7}$ \\
\hline oto08 & Menentukan sendiri tujuan hidup & $\mathbf{- 0 , 5 2 2}$ & 0,341 \\
\hline oto28 & Bertindak berdasarkan rencana yang jelas & $\mathbf{- 0 , 5 1 9}$ & 0,374 \\
\hline oto18 & Tahu apa yang terbaik tanpa tergantung arahan orang & $\mathbf{- 0 , 5 1 7}$ & 0,344 \\
\hline oto29 & Lebih yakin jika mengikuti orang banyak* & $\mathbf{0 , 5 1 3}$ & 0,469 \\
\hline oto33 & Mencari jalan keluar jika keputusan ditolak & $\mathbf{- 0 , 5 0 5}$ & 0,329 \\
\hline oto36 & Performa terbaik ketika didampingi/ diawasi* & 0,370 & $\mathbf{0 , 5 9 5}$ \\
\hline oto30 & Pasrah pada apa yang menurut orang lain yang terbaik* & 0,508 & $\mathbf{0 , 5 9 5}$ \\
\hline oto19 & Berkerja berdasar rencana yang dibuat orang lain* & 0,426 & $\mathbf{0 , 5 8 7}$ \\
\hline oto10 & Tidak berdaya jika orang lain sudah memutuskan* & 0,536 & $\mathbf{0 , 5 8 3}$ \\
\hline oto26 & Cemas jika pilihan berbeda dari orang terdekat* & 0,515 & $\mathbf{0 , 5 1 9}$ \\
\hline oto38 & Tidak ada pengawas mempengaruhi cara berkerja* & 0,435 & $\mathbf{0 , 5 0 9}$ \\
\hline oto09 & Tidak berani bertindak tanpa perintah* & 0,474 & $\mathbf{0 , 5 0 4}$ \\
\hline oto17 & Membentuk diri sendiri di masa depan & $-0,408$ & $\mathbf{0 , 4 5 2}$ \\
\hline Ket: * item unfavorable & &
\end{tabular}

Hasil EFA menunjukkan bahwa keempat subskala seluruhnya terdiri atas dua dimensi. Uniknya, setiap dimensi terdiri atas itemitem yang mengelompok berdasarkan apakah item tersebut unfavorable (faktor $1 / \mathrm{f} 1$ ) dan favorable (faktor 2/ f 2), bukan berdasarkan dimensi teoretisnya. Setiap subskala merupakan skala multidimensional sehingga perhitungan reliabilitas menggunakan rumus stratified alpha coefficient $\left(\alpha_{\mathrm{s}}\right)$ (Widhiarso \& Ravand, 2014). Diperoleh hasil bahwa antara faktor 1 dan faktor 2 di setiap subskala berkorelasi lemah atau tidak berkorelasi sama sekali (lihat tabel 8). Temuan itu mengindikasikan bahwa setiap dimensi mengukur konsep-konsep yang berbeda (Furr, 2011).
Peneliti mengulang kembali analisis reliabilitas dan EFA dengan rotasi Varimax karena dimensi terbukti tak berkorelasi. Kesimpulan akhir tahap 1 adalah bahwa proses eksplorasi dan seleksi item subskala SK-WIRA menunjukkan sejumlah hasil yang tidak terduga. Pertama, subskala 1-4 dari yang semula berisi $40-48$ item per subskala tereduksi menjadi masing-masing 16, 17, 15, dan 14 item saja. Kedua, dimensionalitas subskala pun tidak sesuai dengan konsep awal motivasi berprestasi, keinovatifan, pengambilan risiko, dan kemandirian yang aspek-aspeknya mengacu pada literatur. Setiap subskala terdiri atas dua dimensi yang berkorelasi lemah atau tidak berkorelasi signifikan, menghasilkan 
skala multidimensional dengan dimensi tak berkorelasi (multidimensional scale with

uncorrelated dimensions).

Tabel 8.

Hasil Pemeriksanaan Dimensionalitas dan Reliabilitas Subskala SK-WIRA

\begin{tabular}{|c|c|c|c|c|c|c|c|c|}
\hline \multirow[b]{2}{*}{ Subskala } & \multicolumn{2}{|c|}{ N Item } & \multicolumn{2}{|c|}{ Mean $(S D)$} & \multirow[b]{2}{*}{$r_{f 1-f 2}$} & \multicolumn{2}{|c|}{$\alpha$} & \multirow[b]{2}{*}{$\alpha_{s}$} \\
\hline & f 1 & f 2 & f 1 & $\mathrm{f} 2$ & & f 1 & f 2 & \\
\hline Motivasi Berprestasi & 10 & 6 & $30,04(6,7)$ & $24,67(2,7)$ & $0,189^{*}$ & 0,855 & 0,719 & 0,836 \\
\hline Keinovatifan & 10 & 7 & $35,03(7,1)$ & $31,39(3,4)$ & 0,165 & 0,904 & 0,826 & 0,878 \\
\hline Pengambilan Risiko & 11 & 4 & $32,72(8,1)$ & $17,94(2,0)$ & 0,035 & 0,874 & 0,699 & 0,862 \\
\hline Otonomi & 9 & 5 & $26,23(6,8)$ & $19,44(2,9)$ & $-0,107$ & 0,876 & 0,767 & 0,859 \\
\hline
\end{tabular}

Atas dasar hal tersebut, dapat diinterpretasikan bahwa kedua dimensi mengukur dua konstruk yang berbeda dan perlu dipastikan di tahap selanjutnya. Dua konstruk tersebut adalah karakter nonwirausaha yang seluruhnya berisikan itemitem unfavorable, sementara karakter wirausaha adalah kumpulan item-item favorable. Karakter wirausaha ditandai dengan adanya motivasi berprestasi, keinovatifan, pengambilan risiko, dan kemandirian. Seorang wirusahawan adalah mereka yang: 1) bermotivasi berprestasi tinggi, yakni berorientasi tinggi pada pencapaian hasil kerja terbaik, berupaya pada peningkatan kapasitas diri dan keahlian, dan berupaya pada perbaikan performa dan peningkatan standar kerja, 2) inovatif, yakni bersikap positif terhadap perubahan dan pembaruan dan mau menyesuaikan diri dengan pembaruan, 3) berani mengambil risiko dengan memahami potensi untung-rugi dari pilihan dan berhatihati (berpikir rasional) dalam mengambil keputusan, dan 4) mandiri, yakni mampu menentukan sendiri tujuan, dapat bekerja tanpa pengaturan orang lain, dan berani mempertahankan pilihan pribadi. Keempat dimensi karakter wirausaha ini merupakan dimensi-dimensi asli Skala Karakter Wirausaha.

Sementara itu, karakter bukan wirausaha, merupakan kebalikan dari karakter wirausaha: 1) kebalikan motivasi berprestasi, yaitu preferensi pada kenyamanan yang tampak pada kecenderungan untuk berada pada lingkungan yang nyaman atau familiar, dan menghindari kegagalan dengan memilih pekerjaan dengan standar minimal, 2) kebalikan dari keinovatifan, resistensi terhadap perubahan yang ditandai dengan sikap mempertahankan kebiasaan dan mencurigai inovasi, dan keengganan menyesuaikan diri dengan perubahan, 3) kebalikan dari pengambilan risiko, tidak adaptif terhadap risiko dengan pesimisme lantaran pengalaman gagal, tidak memperhitungkan risiko dalam pengambilan keputusan, dan menolak kegagalan, dan 4) kebalikan otonomi, tergantung pada orang lain untuk mengarahkan dalam mengambil keputusan bertindak dan untuk mengawasi dalam mengerjakan suatu tugas. Empat dimensi baru karakter non-wirausaha ini dirumuskan dari hasil mencermati kembali substansi item-item unfavorable dalam Skala Karakter Wirausaha. Temuan tentang karakter non-wirausaha tergolong baru dalam khazanah keilmuan psikologi kewirausahaan yang patut diteliti lebih lanjut.

\section{Tahap 2 Validitas Konstruk}

Setiap subskala memiliki dua dimensi yang tak berkorelasi sehingga memunculkan perkiraan bahwa penelitian ini akan menghasilkan dua skala, yaitu Skala Karakter Wirausaha/ SK-WIRA dan Skala Karakter Non-Wirausaha/ SK-NWIRA. SKWIRA berisikan item-item favorable dari variabel motivasi berprestasi, keinovatifan, pengambilan risiko, dan kemandirian, sementara SK-NWIRA berisi item-item unfavorable. Hal tersebut dipastikan lewat 
pemeriksaan validitas konstruk dengan Barlett's Tes of Spherity $=856,706$ Confirmatory Factor Analysis/ CFA.

SK-WIRA. Skala ini terdiri atas 22 item yang terbagi dalam empat dimensi, yaitu: motivasi berprestasi, keinovatifan, pengambilan risiko, dan kemandirian. Pemeriksaan dimensionalitas dengan EFA $(\mathrm{PAF}$, rotasi Promax, eigenvalue $=4)$ menunjukkan nilai $\mathrm{KMO}=0.823$ dan

$(\mathrm{p}<0.01)$. Tampilan grafik scree plot seluruh item membentuk satu dimensi sehingga skala ini bersifat unidimensional dan tersusun atas empat aspek yang berkorelasi. Sementara itu, hasil analisis reliabilitas SKWIRA menunjukkan $\alpha=0.863$. Tabel 9 memuat factors loading item-item dalam SK-WIRA.

Tabel 9.

Factors Loading Item-item dalam SK-WIRA

\begin{tabular}{|c|c|c|c|c|c|}
\hline \multirow{2}{*}{$\begin{array}{l}\text { Nomor } \\
\text { Item }\end{array}$} & \multirow[t]{2}{*}{ Inti Pernyataan } & \multicolumn{4}{|c|}{ Faktor } \\
\hline & & 1 & 2 & 3 & 4 \\
\hline inv01 & Senang masyarakat berinovasi & $\mathbf{0 , 8 1 5}$ & & & \\
\hline inv02 & Bersyukur dengan zaman yang penuh dengan inovasi & 0,666 & & & \\
\hline inv03 & Belajar untuk menyesuaikan diri dengan perkembangan & 0,665 & & & \\
\hline inv04 & Mengikuti berita-berita perkembangan inovasi & 0,608 & & & \\
\hline inv05 & Ikut memanfaatkan teknik-teknik baru & $\mathbf{0 , 5 7 4}$ & & & \\
\hline inv06 & Yakin teknik baru memudahkan hidup manusia & 0,554 & & & \\
\hline inv07 & Mengumpulkan modal agar dapat memakai teknologi baru. & 0,498 & & & \\
\hline oto01 & Membentuk sendiri diri saya menjadi pribadi seperti apa & & $\mathbf{0 , 7 4 0}$ & & \\
\hline oto02 & Tahu apa yang terbaik untuk masa depan & & $\mathbf{0 , 7 1 6}$ & & \\
\hline oto03 & Saya menentukan sendiri tujuan dan arah hidup saya. & & 0,627 & & \\
\hline oto04 & Dapat bekerja dengan baik tanpa perlu diawasi & & 0,614 & & \\
\hline oto05 & Berani berpendapat untuk mempertahankan pilihan & & $\mathbf{0 , 3 9 6}$ & & \\
\hline $\mathrm{mb01}$ & Mencari cara agar tugas selesai dengan sempurna & & & 0,618 & \\
\hline mb02 & Biasa berpikir keras untuk memecahkan masalah. & & & $\mathbf{0 , 5 8 0}$ & \\
\hline $\mathrm{mb03}$ & Meningkatkan standar untuk hasil kerja & & & $\mathbf{0 , 5 6 9}$ & \\
\hline mb04 & Berinisiatif mencari solusi lain yang lebih memuaskan & & & $\mathbf{0 , 5 3 0}$ & \\
\hline mb05 & Ingin belajar lebih banyak hal lagi & & & 0,480 & \\
\hline mb06 & Belajar untuk mengantisipasi persoalan baru & & & 0,473 & \\
\hline pr01 & Memahami untung-rugi sebelum membuat keputusan & & & & $\mathbf{0 , 7 8 1}$ \\
\hline pr02 & $\begin{array}{l}\text { Mendengarkan pendapat pro dan kontra dalam membuat } \\
\text { keputusan }\end{array}$ & & & & $\mathbf{0 , 5 5 9}$ \\
\hline pr03 & Mengantisipasi kegagalan dengan strategi alternatif & 0,349 & & & $\mathbf{0 , 4 9 2}$ \\
\hline pr04 & $\begin{array}{l}\text { Mempertimbangkan faktor penyebab kegagalan dalam } \\
\text { membangun rencana }\end{array}$ & & & & $\mathbf{0 , 2 1 9}$ \\
\hline
\end{tabular}

Keterangan: inv $=$ keinovatifan, oto $=$ otonomi, $m b=$ motivasi berprestasi, $p r=$ pengambilan risiko

Tabel 10.

Indikator Model Fit SK-WIRA

\begin{tabular}{ccc}
\hline Indikator & Nilai & Kriteria \\
\hline$\chi^{2} / d f$ & $244,077 / 205$ & $2: 1 / 3: 1$ \\
$p$ & 0,0320 & $\mathrm{p}>0,05$ \\
\hline RMSEA & 0,038 & $<0,07$ \\
\hline CFI & 0,943 & $>0,95$ \\
\hline TLI & 0,936 & $>0,95$ \\
\hline SRMR & 0,069 & $<0,08$ \\
\hline Keterangan: $\chi^{2} / d f=$ chi-square/ degree & of freedom; \\
RMSEA = Root mean square error of approximation; CFI & Comparative Fit Index; TLI = Tucker-Lewis Index; \\
SRMR = Standardised root mean square residual
\end{tabular}

Index; $\mathrm{SRMR}=$ Standardised root mean square residual
Tabel 11.

Matriks Korelasi Faktor-Faktor SK-WIRA

\begin{tabular}{llll}
\hline Faktor & 1 & 2 & 3 \\
\hline 1 & & & \\
2 & 0,441 & & \\
3 & 0,503 & 0,350 & \\
4 & 0,442 & 0,344 & 0,392 \\
\hline
\end{tabular}

Peneliti memeriksa struktur internal Skala Karakter Wirausaha dengan prosedur second-order CFA. Hasil menunjukkan indikator cukup terpenuhi menurut kriteria 
model fit (Hooper, Coughlan, \& Mullen, 2008) sebagaimana tersaji dalam Tabel 10, dengan nilai RMSEA dan SRMR model memenuhi kriteria model fit. Kurang terpenuhinya nilai $\chi^{2} / d f$, CFI, dan TLI ditengarai disebabkan oleh ukuran sampel dan korelasi antar faktor dalam SK-WIRA yang tergolong moderat, berkisar antara 0,35-0,5 (lihat Tabel 11).

SK-NWIRA. Format awal SK-NWIRA berisi 40 item yang berasal dari hasil pengujian psikometrik tahap 1 . SK-NWIRA terdiri atas empat dimensi, yaitu preferensi kenyamanan, resistensi terhadap inovasi, tidak adaptif terhadap risiko, dan ketergantungan pada orang lain. Pemeriksaan dimensionalitas dengan EFA menunjukkan nilai $\mathrm{KMO}=0,906$ dan Barlett's Tes of Spherity $=2994,548$ ( $\mathrm{p}<0,01)$. Berdasarkan tampilan scree plot, seluruh item membentuk satu dimensi dan seluruh aspek berkorelasi. Berdasarkan EFA, dilakukan kembali seleksi item sehingga tersisa 29 item yang memenuhi kriteria memiliki factors loading $>0,30$. bukan item cross-loading, dan memiliki koefisian korelasi item-total $\left(\mathrm{r}_{\mathrm{i}-\mathrm{x}}\right)>0,30$. Hasil analisis reliabilitas menunjukkan koefisien $\alpha=$ 0,930. Tabel 12 memuat factors loading item-item dalam SK-NWIRA.

Tabel 12.

Factors Loading Item-item dalam SK-NWIRA

\begin{tabular}{|c|c|c|c|c|c|}
\hline \multirow{2}{*}{$\begin{array}{l}\text { Nomor } \\
\text { Item }\end{array}$} & \multirow[t]{2}{*}{ Inti Pernyataan } & \multicolumn{4}{|c|}{ Faktor } \\
\hline & & 1 & 2 & 3 & 4 \\
\hline n.oto01 & Cemas ketika berbeda pilihan dengan orang terdekat & 0,858 & & & \\
\hline n.oto02 & Performa terbaik ketika didampingi dan diawasi & 0,662 & & & \\
\hline n.oto03 & Pasrah pada apa yang menurut orang lain terbaik & 0,631 & & & \\
\hline n.oto04 & Ada tidaknya pengawas mempengaruhi cara bekerja & 0,598 & & & \\
\hline n.oto05 & Tidak berdaya jika orang lain sudah membuat keputusan & 0,598 & & & \\
\hline n.oto06 & Lebih yakin ketika mengikuti mayoritas & 0,588 & & & \\
\hline n.oto07 & Tanpa ada perintah, tidak berani bertindak & 0,464 & & & \\
\hline n.oto08 & Selalu butuh arahan tentang apa yang harus dilakukan & 0,439 & & & \\
\hline n.inv01 & Banyaknya inovasi hanyalah tipuan & & 0,752 & & \\
\hline n.inv02 & Kembali pada cara-cara yang lama & & 0,701 & & \\
\hline n.inv03 & Tetap pada hal yang tradisional kecuali terpaksa & & 0,699 & & \\
\hline n.inv04 & Termasuk orang yang ketinggalan zaman (kurang update) & & 0,657 & & \\
\hline n.inv05 & Mempertahankan tradisi & & 0,572 & & \\
\hline n.inv06 & Bertahan dengan prosedur yang lama & & 0,520 & & \\
\hline n.inv07 & Menyesal mencobanya hasil prosedur baru & & 0,463 & & \\
\hline n.inv08 & Mendukung masyarakat kembali pada hal-hal tradisional & & 0,428 & & \\
\hline n.mb01 & Sedapatnya saja mengerjakan tugas di luar keahlian & & & 0,702 & \\
\hline n.mb02 & Lebih yakin bekerja dengan bantuan orang lain & & & 0,672 & \\
\hline n.mb03 & Enggan bekerja sendirian & & & 0,644 & \\
\hline n.mb04 & Berpegang pada standar minimal dalam bekerja & & & 0,559 & \\
\hline n.mb05 & $\begin{array}{l}\text { Merasa biasa saja melewatkan kesempatan membuktikan } \\
\text { diri }\end{array}$ & & & 0,554 & \\
\hline n.mb06 & Panik jika harus bekerja tanpa rekan yang membantu & & & 0,530 & \\
\hline n.mb07 & Malas menghadapi persoalan-persoalan baru & & & 0,520 & \\
\hline n.mb08 & Mencukupkan diri pada standar minimal & & & 0,511 & \\
\hline n.mb09 & Takut menghadapi tugas di luar kemampuan & & & 0,473 & \\
\hline n.prt01 & Dulit menerima kegagalan & & & & 0,5 \\
\hline
\end{tabular}




\begin{tabular}{lll}
\hline Lanjutan Tabel 12. Factors Loading Item-item dalam SK-NWIRA & \\
\hline n.pr02 & Merasa sulit berkembang karena dukungan yang minim & 0,502 \\
\hline n.pr03 & Menjauhkan diri dari masalah & 0,369 \\
\hline n.pr04 & Benci jika usaha gagal & 0,207 \\
\hline
\end{tabular}

Keterangan: $n . i n v=$ resistensi terhadap inovasi, n.oto $=$ ketergantungan pada orang lain, $n . m b=$ preferensi pada kenyamanan, $n . p r=$ tidak adaptif menghadapi risiko

Peneliti mengkonfirmasi struktur internal SK-NWIRA dengan prosedur second-order CFA. Hasil menunjukkan kriteria untuk model fit yang kurang terpenuhi sebagaimana tampak dalam Tabel 13. Hal tersebut kemungkinan disebabkan oleh rendahnya jumlah responden dalam penelitian ini $(\mathrm{N}=130)$ sementara model yang diuji cukup besar, dan korelasi antarfaktor yang moderat, yakni berkisar antara 0,36-0,58 (lihat Tabel 14). Selain itu, proporsi item di setiap faktor pun tidak seimbang. Dimensi risiko hanya terdiri dari empat item, sementara salah satu itemnya hanya memiliki factor loading 0,207.

Tabel 13.

Indikator Model Fit SK-NWIRA

\begin{tabular}{ccc}
\hline Indikator & Nilai & Kriteria \\
\hline$\chi^{2} / d f$ & $559,902 /$ & $2: 1 / 3: 1$ \\
$p$ & 373 & $\mathrm{p}>0,05$ \\
& $<0,001$ & \\
\hline RMSEA & 0,062 & $<0,07$ \\
\hline CFI & 0,886 & $>0,95$ \\
\hline TLI & 0,875 & $>0,95$ \\
\hline SRMR & 0,067 & $<0,08$ \\
\hline
\end{tabular}

Keterangan: $\chi^{2} / \mathrm{df}=$ chi-square/ degree of freedom; RMSEA = Root Mean Square Error of Approximation; $\mathrm{CFI}=$ Comparative Fit Index; $\mathrm{TLI}=$ Tucker-Lewis Index; SRMR = Standardised Root Mean Square Residual

Tabel 14.

Matriks Korelasi Faktor-Faktor SK-NWIRA

\begin{tabular}{lccc}
\hline Faktor & 1 & 2 & 3 \\
\hline 1 & & & \\
\hline 2 & 0,580 & & \\
\hline 3 & 0,494 & 0,503 & \\
\hline 4 & 0,476 & 0,517 & 0,364 \\
\hline
\end{tabular}

Penelitian ini bertujuan mengembangkan Skala Karakter Wirausaha dan menguji properti psikometrik, berupa dimensionalitas, reliabilitas, dan validitas. Penelitian ini merupakan awal bagi penelitian selanjutnya untuk menyempurnakan kembali skala ini agar dapat digunakan di masa depan untuk kepentingan yang lebih luas. Penelitian menghasilkan temuan yang tak terduga, yaitu munculnya konstruk baru, yaitu karakter non wirausaha, sebagai kebalikan dari karakter wirausaha. Hal ini merupakan temuan baru yang perlu dieksplorasi lebih lanjut sebagai masukan bagi pengembangan psikologi kewirausahaan.

Riset-riset kewirausahaan berbasis pendekatan sifat sejauh ini baru terbatas pada identifikasi sifat-sifat menonjol yang dimiliki oleh wirausahawan yang membedakannya dari orang dengan profesi lain (Brandstätter, 2011; Frese, 2007, 2009; Frese \& Gielnik, 2014; Walter \& Heinrich, 2013). Kecocokan atau ketidakcocokan seseorang untuk berwirausaha cenderung dipandang sebagai spektrum tinggi-rendah dalam kontinum karakter wirausaha, bukan dua karakter yang berbeda. Jika karakter wirausaha dan non wirausaha adalah semacam tipe kepribadian, hal ini dapat bermanfaat bagi pengenalan potensi diri dan orientasi karir generasi muda.

Penelitian ini memiliki beberapa keterbatasan. Pertama, ukuran sampel yang terbilang rendah, yakni hanya 130 orang. Hal ini tidak sesuai dengan standar ideal untuk dilakukannya prosedur CFA, yaitu lebih dari 200 orang (Barrett, 2007) sehingga menyebabkan beberapa indikator model fit tidak terpenuhi. Kedua, kualitas data dikumpulkan kurang sempurna di mana distribusi skor cenderung condong kanan (positively skewed). Ketiga, set awal skala 
karakter ini memuat empat subskala dengan jumlah item yang banyak. Terdapat laporan bahwa para responden kurang optimal dalam menjawab karena kelelahan dan bosan.

Penelitian ini hendak dilanjutkan untuk penyempurnaan kedua skala dengan memperhatikan beberapa hal. Pertama, meningkatkan ukuran sampel menjadi 200500 orang dan sampel diambil dari lokasilokasi yang berbeda di Indonesia sehingga skala ini dapat digeneralisasi untuk digunakan di Indonesia. Kedua, memperbaiki proporsi skala dengan menulis kembali item terutama untuk dimensi pengambilan risiko pada SK-WIRA dan SKNWIRA. Dalam skala yang dikembangkan kali ini, dimensi pengambilan risiko kurang terwakilkan karena jumlah item yang kurang, padahal variabel ini merupakan karakter dominan yang mencirikan seorang wirausahawan (Walter \& Heinrich, 2013). Ketiga, meningkatkan kualitas validitas skala dengan melakukan pemeriksaan validitas konkuren dan prediktif dari SKWIRA dan SK-NWIRA. Hal ini dapat dilakukan dengan mengkorelasikan kedua skala ini dengan pengukuran-pengukuran kewirausahaan lain yang relevan, seperti kepribadian Big Five, intensi wirausaha, efikasi diri wirausaha, dan performa wirausaha.

Terakhir, penelitian ini menghasilkan temuan baru berupa konstruk karakter non wirausaha dengan ciri-cirinya tersendiri. Temuan ini dapat ditindaklanjuti dengan studi eksplorasi untuk menggali langsung konsep karakter wirausaha dan non wirausaha pada orang-orang yang berkiprah sebagai wirausahawan dan tidak hanya menyandarikan konseptualisasi pada literatur. Temuan saat ini menyimpulkan adanya kemungkinan pengaruh budaya pada kewirausahaan, misalnya pada persepsi wirausaha dan intensi berwirausaha (Kristiansen \& Indarti, 2004; Liñán \& Chen, 2009).

\section{SIMPULAN}

Riset konstruksi alat ukur psikologi ini mengembangkan dua skala, yaitu SK-WIRA dan SK-NWIRA. Pengujian properti psikometrik menunjukkan hasil bahwa kedua skala merupakan skala unidimensi. Melalui perhitungan konsistensi internal, kedua skala memiliki reliabilitas yang baik. Terakhir, pengujian validitas menunjukkan model fit kedua skala relatif baik, meski memerlukan penyempurnaan di masa depan. Riset ini menghasilkan temuan menarik bahwa karakter wirausaha (yang mencirikan bahwa seseorang berpotensi menjadi wirausahawan) dan karakter non wirausaha (yang mencirikan bahwa seseorang kurang sesuai atau kurang berkapasitas untuk menjadi wirausahawan) merupakan konsep psikologis yang berbeda.

\section{UCAPAN TERIMA KASIH}

Terima kasih ditujukan kepada LP3M Universitas Muhammadiyah Magelang (UM Magelang) yang telah membiayai penelitian ini melalui skema dana hibah penelitian internal tahun 2018. Terima kasih juga ditujukan kepada mahasiswa-mahasiswa angkatan 2017 di Fakultas Psikologi dan Humaniora UM Magelang yang telah berkontribusi sebagai kolektor data penelitian ini.

\section{DAFTAR PUSTAKA}

Antonites, A. J., \& Wordsworth, R. (2009). Risk tolerance: A perspective on entrepreneurship education. Southern African Business Review, 13(3), 69-85.

Barrett, P. (2007). Structural equation modelling: Adjudging model fit. Personality and Individual Differences, 42(5), 815-824. https://doi.org/10.1016/j.paid.2006.09.0 18.

Brandstätter, H. (2011). Personality aspects of entrepreneurship: A look at five 
meta-analyses. Personality and Individual Differences, 51(3), 222-230. https://doi.org/10.1016/j.paid.2010.07.0 07.

Brockhaus, R. H. (1980). Taking propensity of entrepreneurs. Academy of Management Journal, 23(3), 509-520.

Broeck, A. V. D., Vansteenkiste, M., Witte, H. D., Soenens, B., \& Lens, W. (2010). Capturing autonomy, competence, and relatedness at work: Construction and initial validation of the Work-related Basic Need Satisfaction Scale. Journal of Occupational and Organizational Psychology, 83, 981-1002. https://doi.org/10.1348/096317909X48 1382.

Chen, S., Su, X., \& Wu, S. (2012). Need for achievement, education, and entrepreneurial risk-taking behavior. Social Behavior and Personality, 40(8), 1311-1318.

https://doi.org/http://dx.doi.org/10.2224 /sbp.2012.40.8.1311.

Costello, A. B., \& Osborne, J. W. (2005). Best practices in exploratory factor analysis: Four recommendations for getting the most from your analysis. Practical Assessment, Research \& Education, $10.1-9$. https://doi.org/10.1.1.110.9154.

Frese, M. (2009). Towards a psychology of entrepreneurship: An action theory perspective. Foundations and Trends ${ }^{\circledR}$ in Entrepreneurship, 5(6), 437-496. https://doi.org/10.1561/0300000028.

Frese, M., \& Gielnik, M. M. (2014). The psychology of entrepreneurship. Annual Review of Organizational Psychology and Organizational Behavior, 1, 413438. https://doi.org/10.1146/annurevorgpsych-031413-091326

Furr, R. M. (2011). Scale construction and psychometrics for social and personality psychology. London: SAGE Publications.

https://doi.org/10.4135/9781446287866

Goldsmith, R. E., \& Foxall, G. R. (2003). The measurement of innovativeness. In L. V. Shavinina (Ed.), The International Handbook on Innovation (pp. 321-330). Armsterdam: Elsevier Science.

Hisrich, R., Langan-Fox, J., \& Grant, S. (2007). Entrepreneurship research and practice: A call to action for psychology. American Psychologist, 62(6), 575-589. https://doi.org/10.1037/0003066X.62.6.575.

Hooper, D., Coughlan, J., \& Mullen, M. R. (2008). Structural equation modelling: Guidelines for determining model fit structural equation modelling: Guidelines for determining model fit. The Electronic Journal of Business Research Methods, 6(1), 53-60. https://doi.org/10.1037/1082989X.12.1.58

Kelley, D., Singer, S., \& Herrington, M. (2015). Global Entrepreneurship Monitor - 2015/2016 Global Report. https://doi.org/ISBN: 978-1-939242-051.

Kristiansen, S., \& Indarti, N. (2004). Entrepreneurial intention among Indonesian and Norwegian students. Journal of Enterprising Culture, 12(1), 55-78.

https://doi.org/10.1142/S021849580400 004X.

Liñán, F., \& Chen, Y. W. (2009). Development and cross-cultural application of a specific instrument to measure entrepreneurial intentions. Entrepreneurship: Theory and Practice, 33(3), 593-617. 
https://doi.org/10.1111/j.1540-

6520.2009.00318.x.

Lumpkin, G. T., Cogliser, C. C., \& Schneider, D. R. (2009). Understanding and measuring autonomy: An entrepreneurial orientation perspective. Entrepreneurship Theory and Practice, 33(1), 47-69.

Marcati, A., Guido, G., \& Peluso, A. M. (2008). The role of SME entrepreneurs' innovativeness and personality in the adoption of innovations. Research Policy, 37, 1579-1590. https://doi.org/10.1016/j.respol.2008.06 .004 .

Maulana, A. (2018, Februari). Ubah pemikiran menjadi pegawai, generasi milenial didorong menjadi pengusaha. http://www.unpad.ac.id/2018/02/ubahpemikiran-menjadi-pegawai-generasimilenial-didorong-menjadi-pengusaha/

Mueller, S. L., \& Thomas, A. S. (2000). Culture and entrepreneurial potential: a nine country study of locus of control and innovativeness. Journal of Business Venturing, 16, 51-75.

Palich, L. E., \& Bagby, D. R. A. Y. (1995). Using cognitive theory to explain entrepreneurial risk-taking: Challenging conventional wisdom. Journal of Business Venturing, 10, 425-438.

Rauch, A., \& Frese, M. (2000). Psychological approaches to entrepreneurial success: A general model and an overview of findings. In C. L. Cooper \& I. T. Robertson (Eds.), International Review of Industrial and Organizational Psychology (Vol. 15, pp. 101-142). Chichester: Wiley.

Rauch, A., \& Frese, M. (2007). Born to be an entrepreneur? Revisiting the personality approach to entrepreneurship. In J. R. Baum, M.
Frese, \& R. Baron (Eds.), The Psychology of Entrepreneurship (pp. 41-65). New York: Psychology Press.

Ryan, R. M., \& Deci, E. L. (2000). Selfdetermination theory and the facilitation of intrinsic motivation, social development, and well-Being. American Psychologist, 55(1), 68-78.

Sagie, A., \& Elizur, D. (1999). Achievement motive and entrepreneurial orientation : a structural analysis. Journal of Organizational Behavior, 20. 375-387.

Shane, S., \& Venkataraman, S. (2000). The promise of entrepreneurship as a field of research. Entrepreneurship: Concepts, Theory and Perspective, 25(1), 171-184. https://doi.org/10.1007/978-3-54048543-8_8

Stewart, W. H., \& Roth, P. L. (2001). Risk propensity differences between entrepreneurs and managers: A metaanalytic review. Journal of Applied Psychology, 86(1), 145-153. https://doi.org/10.1037//00219010.86.1.145.

Suryanto, I. (2017, Oktober). Millennials Disarankan untuk Berwirausaha. IDN TIMES.

https://www.idntimes.com/business/economy/imansuryanto/millennials -disarankan-untuk-berwirausaha/full

Utsch, A., \& Rauch, A. (2000). Innovativeness and initiative as mediators between achievement orientation and venture performance. European Journal of Work and Organizational Psychology, 9(1), 4562.

https://doi.org/10.1080/1359432003980 58

Vlachopoulos, S. P., \& Michailidou, S. (2006). Development and initial 
validation of a measure of autonomy, competence, and relatedness in exercise: The Basic Psychological Needs in Exercise Scale. Measurement in Physical Education and Exercise Science, 10(3), 179-201. https://doi.org/10.1207/s15327841mpee 1003_4.

Walter, S. G., \& Heinrich, S. (2013). Who becomes an entrepreneur? A 30-yearsreview of individual-level research and an agenda for future research. Journal of Small Business and Enterprise Development, 22(2), 225-248.
http://dx.doi.org/10.1108/JSBED-092012-0106.

Widhiarso, W., \& Ravand, H. (2014). Estimating reliability coefficient for multidimensional measures: A pedagogical illustration. Review of Psychology, 21(2), 111-121.

Wu, S., Matthews, L., \& Dagher, G. K. (2007). Need for achievement, business goals, and entrepreneurial persistence. Management Research News, 30(12), 928-941.

https: //doi.org/10.1108/0140917071083335. 